\title{
Tempo da Infância: cuidado e violência
}

\author{
Christian Ingo Lenz Dunker ${ }^{1}$
}

\begin{abstract}
Resumo
Nesta comunicação apresento diferenças subjetivas entre a experiência do tempo no adulto e na criança. A infância não é apenas um tempo de vida que possuiria exigências e limites próprios, mas também que se constitui como uma maneira singular de colocar-se no tempo, seja no sentido da duração, seja no sentido da subjetivação de acontecimentos e significações. Disso decorre a hipótese de que o tempo deve ser pensado como um operador clínico incontornável no manejo de intervenções com a criança, particularmente em situação hospitalar ou de adoecimento. A criança em tratamento precisa conjugar sua própria modulação do tempo necessário para intuir, compreender e concluir, os aspectos implicados em sua condição articulando se assim ao tempo da urgência, da emergência ou da convalescência, que determina a lógica institucional da cura. No escopo deste confronto de temporalidades as mesmas ações, consideradas segundo a perspectiva procedimental, podem implicar efetiva experiência de cuidado ou efeitos iatrogênicos de violência. Para ilustrar e conceituar esta proposição retomaremos as práticas helenísticas do cuidado de si, comparando-as com a posição da criança nas sociedades ocidentais no momento da aparição da "infância" (século XVIII) e em nosso contexto contemporâneo de aceleração do tempo e de disseminação do estado de urgência.
\end{abstract}

Palavras chave: psicanálise, temporalidade, violência, cuidado

Dunker, Christian Ingo Lenz. "Tempo da Infância: cuidado e violência", in Anais do 20. Congresso Internacional Sabará de Especialidades Pediátricas

\footnotetext{
${ }^{1}$ Psicanalista e Professor Titular do Departamento de Psicologia Clínica do Instituto de Psicologia da USP. Pós Doutorado pelo Manchester Metropolitan University e Livre Docência pela USP, autor de "Estrutura e Constituição da Clínica Psicanalítica" (Annablume, prêmio Jabuti 2012). Coordenador do Laboratório de Teoria Social, Filosofia e psicanálise da USP, Analista Membro de Escola (A.M.E.) do Fórum do Campo Lacaniano.
} 


\section{Tempo da Infância: cuidado e violência}

\section{Chronos, o deus grego do tempo e suas três cabeças: o homem entre o touro e o leão}

Onde se apresenta as diferentes maneiras de conceber e de estar no tempo levantando a proposição de que o tempo necessariamente nos divide. Como dizia Hegel, "o relógio da história não marca a mesma hora em todos os quadrantes". Colocação necessária para introduzir a ideia de que estamos em "tempos" diferentes, que entre adultos e crianças esse descompasso temporal é maior ainda, e que em situação de adoecimento (hospitalar) este descompasso se multiplica ainda mais.

a. Aeon: tempo cíclico, circular e criativo, mas também o tempo do mito, das origens imemoriais, dos ancestrais.

b. Kayrós: o tempo do acontecimento, do encontro, da contingência.

c. Epos: o tempo da palavra, da história (épica), mas também da suspensão da palavra e do juízo (epochê) ou ainda o tempo da sucessão das eras (épocas).

d. ... e o apocalipse cristão: o tempo que tem um início, logo terá um fim. O tempo da descoberta ou da revelação que retrospectivamente cria o início. De certa forma esta quarta forma de tempo já estava prenunciada pela serpente Anankê (Inevitabilidade, Necessidade) que envolve Cronos.

Estas três mais uma forma de tempo ilustram bem o percurso que a criança faz em sua experiência do tempo, primeiro a alternância, depois o encontro, envolvendo a segmentação de durações, escansões ou intervalos, em seguida o tempo da palavra, com suas histórias épicas e repetições integrado aos parênteses e elipses, culminando neste tempo inesperado de descoberta da finitude.

O adulto ao contrário, especialmente os adultos urbanos de grandes metrópoles, parece estar aderido ao tempo longo do intervalo entre compressão (trabalho) e descompressão (lazer). No interior deste tempo longo, ou tempo frio como diria Braudel, há 
o tempo quente, o tempo dos processos produtivos, marcado pela emergência, urgência e convalescência.

A experiência de adoecer é um parêntese na vida, no interior do qual somos levada a nos subordinar a uma temporalidade que não nos é própria, mas imposta pela doença e pelos tratamentos e procedimentos tomados em relação à ela.

\section{Cabeça de Cronos}

\section{O cuidar como uma relação política}

Alcebíades demanda a Sócrates a arte de governar e este lhe responde "cuida" da tua própria alma, e não "conhece-te a ti mesmo". Daí que a disposição do governo implica cuidar dos outros e deve ser precedida pelo cuidado de si, que implica inúmeras práticas, métodos e preceitos, mas que aqui podem ser concentrar em "encontrar o próprio tempo", no interior de processos que não governamos (como a doença), em lugares dos quais não somos os senhores (como o hospital) e diante de saberes que desconhecemos (como os que subsidiam e determinam os tratamentos).

O transitivismo da experiência de sofrimento e nosso desejo de suspender o cuidado de si para cuidar do outro.

1900 Sócrates Salva Alcebíades do Vício (Pedro Américo)

1959 Os Incompreendidos (Troufaut)

\section{A lógica temporal do sujeito}

Aqui se apresenta, suscintamente, a teoria do tempo lógico desenvolvida por Jacques Lacan em torno da equivalência entre as formas do sujeito e as modalidades de relação ao objeto (imaginário), ao Outro (simbólico) e ao ato (Real).

a. o instante de ver: a imediaticidade (Aeon)

1907 The Sick Child (Edward Munch)

b. o tempo para compreender: a reflexividade (Mithos e Epos)

1891 The Doctor (Luke Fieldes) 
c. o instante de concluir: do ato ao juízo (Kayrós e Apocalipse)

(1880) Criança Doente (Francisco Bonde)

\section{As Patologias Temporais do Cuidado}

a. a criança como pequeno adulto: a criança prisioneira do instante de ver. Submetida á pressa, ao entendimento imediato, e ao mesmo tempo o centro da cena, o ponto de convergência para o qual se vertem todos os olhares. Esta é uma criança que não pode crescer, pois já está "crescida" como "sua majestade o bebê", que tiranicamente exige súditos aos quais suborna com sua cota inesgotável de capital amoroso. Pode ser a criança que se ama infinitamente e eternamente. É a criança que o adulto projeta e com a qual ele se identifica, esquecendo-se que esta criança não é "aquela criança que você foi um dia".

1656 Meninas (Velázquez)

b. A criança destituída de sujeito: é aquela que está subordinada aos cuidados do Outro, adulto. A ela não se pede anuência, não se negocia prazos, não se concede nada além de obedecer ao que o adulto quer e precisa. Tudo isso "em nome do seu próprio bem". A violência que recai sobre ela é o furto de sua palavra, a substituição do tempo no qual ela poderia se manifestar, ainda que como resistência e indocilidade.

1653 Famíia (Jen Guerritz)

c. A criança operativa: é aquela que deve produzir, performar, mesmo que seja por conformar-se à adequação esperada para o momento. Ela deve estar sempre concluindo, brilhando aos olhos dos cuidadores para melhor confirmar sua excelência nesta prática do cuidado.

2006 Pequena Mis Sunshine (Jonathan Dayton e Valerie Faris)

Time of Infanthood: care and violence 


\begin{abstract}
:
In this communication we present some subjective differences between temporality in child and adults. Infanthood is not only a period of life witch has some inherent properties and limits but also a time that constitutes itself as a singular way of positing oneself in time, either we consider time as duration or in the sense of the subjectification of things and their meanings. We can deduced from this assumptions the hypothesis that time must be considered as a crucial clinical operator in the maneuver of interventions upon a child, particularly in hospitalization and illness. The child in treatment must assemble his or her own temporal integration witch comprehends intuition, comprehension and conclusion, the aspects embedded in his or her medical condition. Far from that he or she must accept and integrate in this process the temporality of emergency, urgency and convalescence with determines the institutional process of cure. In the space of this confrontation between temporalities, considered from a methodological perspective, the same action could be taken as proper care or as iatrogenic violence. In order to illustrate and conceptualized this phenomena we will take examples from the old Hellenistic practice of taking-care of oneself, from the occidental period when infancy emerges as a separate moment of life, and from our own contemporary era and its contexts of time acceleration and generalized urgency.
\end{abstract}

Keywords: Psychoanalysis, temporality, care and violence

\title{
Referências
}

ARIÉS, P. (1973) História Social da Família e da Infância. Rio de Janeiro, Guanabara, 1978

DUNKER, Christian Ingo Lenz Dunker. Estrutura e Constituição da Clínica Psicanalítica. São Paulo, Annablume, 2012 (Coleção Ato Psicanalítico).

LACAN, J. (1945) O tempo lógico e a asserção da certeza antecipada: um novo sofisma. In

Escritos, Rio de Janeiro, Jorge Zahar, 1998, p. 197-214. 